We acknowledge the co-operation of our fellow practitioners and their secretaries and, in particular, the invaluable work of Mrs Helen Mehta in organising clinics and collecting data. We thank Mrs E Pay for secretarial help.

\section{References} \\ 1 Duncan, A H, Health Bulletin, 1970, 28, 54. \\ 2 Scottish Home and Health Department, Towards an Integrated Child \\ Health Service. Edinburgh, HMSO, 1973. \\ ${ }^{3}$ Gruer, K T, and Heasman, M A, British Medical fournal, 1970, 2, 289. \\ 4 Bain, D J G, and Haines, A J, Health Bulletin, 1974, 32, 11.
}

${ }^{5}$ Carstairs, V, and Howie, V, Health Service in Population of 250,000. Scottish Health Service Studies No 24. Edinburgh, SHHD, 1972.

${ }^{6}$ Forfar, J O, and Arneil, G C, Textbook of Paediatrics. Edinburgh, Churchill Livingstone, 1974.

7 Joseph, M, and MacKeith, R C, A New Look at Child Health. London, Pitman Medical, 1966.

${ }^{8}$ Miller, F J W, et al, Growing up in Newcastle upon Tyne: A continuing study of health and illness in young children within their families. London, Oxford University Press for the Nuffield Foundation, 1960.

${ }^{9}$ McKeown, T, Medicine in Modern Society. London, Allan and Unwin, 1965.

10 Scottish Home and Health Department, General Practitioners in the Hospital Service. Edinburgh, HMSO, 1973.

${ }^{11}$ Marsh, G N, and Tompkins, A B, British Medical fournal, 1969, 2, 106.

12 Harper, W F, Auld, A, and Murray, A, Health Bulletin, 1972, 31, 281.

\title{
Peripheral paediatric clinics: survey and medical audit
}

\author{
S D V WELLER
}

British Medical fournal, 1975, 4, 390-393

\begin{abstract}
Summary
The work of the paediatric clinics in nine generalpractitioner hospitals in country towns in the Bath Health District during 1972 was analysed with respect to the pattern of referrals and methods of management. It is concluded that no child suffered harm from being seen in a clinic without full laboratory and $x$-ray facilities. Nearly $98 \%$ of the consultations were deemed, even with a long period of hindsight, to have been completely satisfactory. The tremendous benefit to the patients and their families of being seen in a hospital near their home is not bought at the cost of a second-rate medical service.
\end{abstract}

\section{Introduction}

In a comparison of paediatric clinics held in the general hospital in Bath with those held in country towns in the district, patients expressed a strong preference for the latter, peripheral clinics on the grounds of cost and convenience. ${ }^{1}$ The important consideration, however, is the standard of care offered. It would be a poor gain to save the patient trouble and cash if the quality of care he receives is reduced. Marsh and Tompkins ${ }^{2}$ reviewed the work of a clinic conducted by a consultant paediatrician at a group practice over 18 months; the family doctor was usually present. They felt that there were advantages to both the doctors and patients and that such consultations were medically adequate. Gruer ${ }^{3}$ commented on a large number of consultations in southern Scotland that entailed only a single visit, with no review, which were clearly deemed satisfactory despite the lack of special facilities.

Recently the need for some investigations that had been regarded as mandatory has been questioned, ${ }^{4}$ and Leonard et $a l^{5}$ pointed out the small contribution to diagnosis made by a biochemical profile in nearly 3000 children. Any paediatrician who regards a full blood count, chest $x$-ray examination, and serum chemistry as part of the routine clinical examination of every child would consider any consultation without even the possibility of these tests as grossly inadequate. I therefore

Bath Health District

S D V WELLER, MD, FRCP, consultant paediatrician declare myself as one who has tended over the years to do fewer investigations and who is no longer upset at the prospect of conducting some clinics in what is kept to look like an ordinary room. There is no white coat, and diagnostic instruments are kept out of sight.

In the Bath Health District (population 350000 ) three peripheral clinics are conducted each week by a consultant paediatrician. Any child from a country clinic who needs investigations is admitted to the ward in the general hospital in Bath on a day-patient basis to avoid an overnight stay.

\section{Present study}

In view of the difficulty of comparing the work of different consultants or asking one colleague to check the performance of another I studied the quality and efficiency of consultations in the country clinics by following up children seen in 1972 by one consultant. My aim was to see whether the care offered had seemed adequate at the time and whether it had proved to be as satisfactory in the light of subsequent progress. Data were collected on every consultation during the year at clinics conducted in nine peripheral hospitals, which I visited. Information was gathered on the later course of the problem for which the child was referred.

Often it was easy to say whether or not the decision made had proved correct. When there was doubt or when the child had been discharged from the clinic the family doctor was asked for particulars; he was specifically asked whether he had thought at the time that the consultant's action was right and whether events had made him revise this view. In a few instances the parents were asked for information and even to give their opinions.

In 1972 study leave and illness prevented me from doing these clinics for a total of 18 weeks. The survey therefore covers not only my performance but also that of four other specialists who undertook. locum work.

The nine hospitals were usually visited monthly; occasionally clinics were cancelled because of national holidays or leave. When demand was increased extra clinics were arranged.

\section{BOOKINGS AND ATTENDANCES}

Altogether 101 clinics were held, with an average of 11 patients booked per session (table I). There were 27 defaulters among the new patients and 53 among the old ones; this latter figure includes patients who defaulted more than once, whose families were usually known to the social services. Defaulters among new referrals were mainly cases referred from the wards for a check on their progress since discharge.

Actual attendances are shown in table I. New patients are separated into direct referrals from family doctors and those whose visit had been requested by the ward to ensure that the child who had been sent home before complete recovery, perhaps for social reasons, had 
TABLE I-Source of referrals and rates of attendance of new and old patients

\begin{tabular}{|c|c|c|c|c|c|c|c|c|c|c|}
\hline \multirow{3}{*}{ Hospital } & & \multirow{3}{*}{$\begin{array}{l}\text { No of } \\
\text { clinics }\end{array}$} & \multicolumn{3}{|c|}{ Bookings } & \multicolumn{5}{|c|}{ Attendances } \\
\hline & & & \multicolumn{3}{|c|}{ Patients booked } & \multicolumn{3}{|c|}{ New patients } & \multicolumn{2}{|c|}{ Old patients } \\
\hline & & & New & Old & Total & From GP & Ex-ward & Total & Individuals & Attendances \\
\hline $\begin{array}{l}\text { Chippenham } \\
\text { Paulton .. } \\
\text { Warminster } \\
\text { Trowbridge } \\
\text { Frome .. } \\
\text { Melksham } \\
\text { Shepton Mallet } \\
\text { Malmesbury } \\
\text { Devizes .. }\end{array}$ & $\begin{array}{l}\cdots \\
\cdots \\
\cdots \\
\cdots \\
\cdots \\
\cdots \\
\cdots\end{array}$ & $\begin{array}{r}11 \\
11 \\
11 \\
12 \\
12 \\
13 \\
9 \\
11 \\
11\end{array}$ & $\begin{array}{l}42 \\
33 \\
77 \\
68 \\
42 \\
59 \\
32 \\
35 \\
54\end{array}$ & $\begin{array}{r}98 \\
55 \\
69 \\
98 \\
64 \\
102 \\
34 \\
61 \\
81\end{array}$ & $\begin{array}{r}140 \\
88 \\
146 \\
166 \\
106 \\
161 \\
66 \\
96 \\
135\end{array}$ & $\begin{array}{l}39 \\
28 \\
68 \\
52 \\
36 \\
51 \\
24 \\
33 \\
41\end{array}$ & $\begin{array}{l}3 \\
3 \\
5 \\
9 \\
6 \\
3 \\
6 \\
1 \\
7\end{array}$ & $\begin{array}{l}42 \\
31 \\
73 \\
61 \\
42 \\
54 \\
30 \\
34 \\
48\end{array}$ & $\begin{array}{l}46 \\
34 \\
41 \\
43 \\
40 \\
40 \\
22 \\
31 \\
36\end{array}$ & $\begin{array}{l}90 \\
51 \\
64 \\
93 \\
63 \\
92 \\
32 \\
53 \\
71\end{array}$ \\
\hline \multicolumn{2}{|l|}{ Total } & 101 & 442 & 662 & 1104 & 372 & 43 & 415 & 333 & 609 \\
\hline
\end{tabular}

not suffered medically. Early discharge was fairly common when parents found difficulty visiting every day and the child showed signs of stress. Old patients are tabulated as individuals and as "attendances."

The fact that new patients outnumbered old ones, and also that old patients attended on average less than twice in the year under review, indicates that the children were returned to their family doctors at the first opportunity, and possibly sooner than from many paediatric departments. In fact, this policy was pursued as rigorously for new referrals.

\section{NEW PATIENTS}

Table II gives some of the possible outcomes of a consultation; others-for example, onward referral to a colleague-are not included. Several patients are mentioned twice-for example, when they were admitted for investigations and then referred back to the country clinic for review; this was often needed, as mother and child would usually have gone home once the tests were completed but before any reports were available. The policy was to send details to the family doctor and also a letter to the parents to outline the results and explain their meaning. When the findings were abnormal it was usual to see the child and parents again to discuss the matter further, so as to be sure that the significance of the tests was understood, that reassurance was accepted, and that any treatment would be willingly and regularly given.

Immediate discharges-Many children had waited up to a month to be seen. Others had come for review after inpatient care. In several cases the condition had resolved and further supervision was unnecessary. Some parents needed reassurance that treatment was already optimal or that a trivial complaint had no sinister import. Yet other children were seen for a check on some feature noted in the neonatal period. The diagnoses are set out in broad groups in table III. In the small prospective series of Kerr et $a l^{1}$ a discharge rate of $38 \%$ was noted among new patients seen at country clinics (19 out of 50 patients). The rate for the year studied here was $34 \%$ (141 out of 415 patients). In the survey by Kerr et al there were 11 immediate discharges among the 21 new patients seen in the district hospital in Bath. The discharge rate was not apparently altered by the fact that investigations were readily available.

Day tests-About one-seventh of all new patients (and a few old patients) underwent investigations as day patients. It was common for a child to have several complaints. Their problems are set out in table III. No child was found to have any anomaly or disorder needing a change of the policy being followed pending the results of the tests.

Admission in attack-Children who get recurrent attacks of some sort often attend outpatient departments when in the best of health.
TABLE III-Diagnostic categories of new and old patients

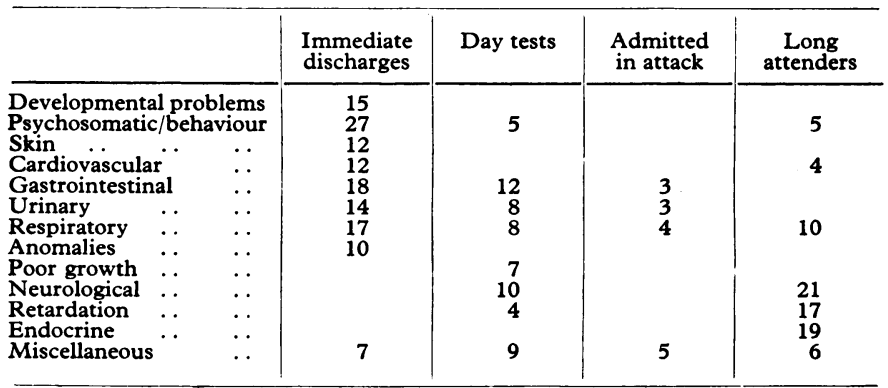

Fifteen children, however, were put down to be investigated during an attack. Four were "chesty," three suffered episodes of abdominal pain, and three complained of intermittent dysuria. Five children had attacks peculiar to themselves, which varied from sweating to loss of use of a limb. Seven children continued to have attacks that never seemed bad enough to warrant admission. Of those who were admitted none was found to have appreciable organic disease. This is plainly only a small group, even for a year of clinics, but both it and the previous group suggest that admission in attacks and investigation on a day basis yielded a fairly low dividend. The emotional element in these children appeared to outstrip in importance their physical disease.

\section{OLD PATIENTS}

Inevitably some old patients had been seen regularly, but not necessarily often, for years. Handicapped children may not be good travellers, and long, cross-country journeys on buses and trains may be a great ordeal for them. The survey by Kerr et al showed dramatically how much easier it is for the family if supervision can be at the local hospital.

\section{LONG ATTENDERS}

The long attenders differed greatly from the children already described. Most of them presented multiple problems, but they are classified in table III under their main one. When the diagnoses are considered the social convenience to patients over the years is immense. This is especially true for the families of children with handicaps or

TABLE II-New patients. (Outcome of consultation)

\begin{tabular}{|c|c|c|c|c|c|c|c|c|}
\hline \multicolumn{3}{|c|}{ Hospital } & Attended & Discharged & Reviewed locally & "Day tests" & To be admitted in attack & Admitted at once \\
\hline $\begin{array}{l}\text { Chippenham } \\
\text { Paulton .. } \\
\text { Warminster } \\
\text { Trowbridge } \\
\text { Frome } \quad . . \\
\text { Melksham } \\
\text { Shepton Mallet } \\
\text { Malmesbury } \\
\text { Devizes . . }\end{array}$ & $\begin{array}{l}\ldots \\
\ldots \\
\cdots \\
\cdots \\
\cdots \\
\ldots\end{array}$ & $\begin{array}{l}\ldots \\
\ldots \\
\therefore \\
\ldots \\
\ldots \\
\ldots\end{array}$ & $\begin{array}{l}42 \\
31 \\
73 \\
61 \\
42 \\
54 \\
30 \\
34 \\
48\end{array}$ & $\begin{array}{l}11 \\
11 \\
31 \\
13 \\
5 \\
20 \\
12 \\
16 \\
22\end{array}$ & $\begin{array}{r}19 \\
9 \\
27 \\
25 \\
24 \\
20 \\
11 \\
14 \\
15\end{array}$ & $\begin{array}{r}6 \\
4 \\
3 \\
13 \\
8 \\
11 \\
11 \\
4 \\
6 \\
3\end{array}$ & $\begin{array}{l}4 \\
2 \\
1 \\
1 \\
3 \\
1 \\
1 \\
2\end{array}$ & $\begin{array}{l}2 \\
3 \\
1 \\
2 \\
2 \\
1 \\
1 \\
2\end{array}$ \\
\hline Total & & & 415 & $141(34.0 \%)$ & $164(39.5 \%)$ & $58(14.0 \%)$ & $15(3.6 \%)$ & $14(3 \cdot 4 \%)$ \\
\hline
\end{tabular}


those for whom a day in Bath meant loss of a day's work or a day's schooling or both.

\section{Medical audit}

The 415 new patients and 609 attendances by old patients were reviewed to assess their care. This included not only medical management but also communications between consultant and parent on the one hand and between consultant and family doctor on the other. Out of all 1024 attendances information was obtained on 1016 $(99 \cdot 2 \%)$. The eight not documented are excluded.

Performance was deemed to be unsatisfactory on several grounds. Firstly, when there was a delay in diagnosis or a wrong diagnosis. Secondly, when there was failure to communicate adequately with parents or doctor. Thirdly, when a child was discharged and the doctor or parents said later that they would have preferred continued contact-the doctor sometimes referred the patient back promptly; the parent usually accepted the situation. Fourthly, when treatment, supervision, or follow-up had failed at the hospital end. Persistent defaulting was reported to the general practitioner, who either tried to arrange further appointments or himself accepted the responsibility for continuing care; this was not necessarily regarded as a failure. Finally, management was considered unsatisfactory when, in retrospect, I would have preferred to manage the problem in the district hospital with the support of the laboratory, $x$-ray department, or a dietitian.

A consultation accepted as satisfactory signifies that the general practitioner was satisfied with the situation at the time and remained so two years or more later. In fact, the practitioner was asked for this assurance in connection with 438 consultations, including all patients who were discharged. I also had to be satisfied. Of the 1016 consultations $23(2 \cdot 3 \%)$ were regarded as less than satisfactory. Some details of these are given below.

\section{MEDICAL FAILURES}

Diagnostic failure (4 cases)-Battered baby; not immediately recognised, investigated for bruising. "Pre-battered" baby; investigated for retardation, social problems recognised at first review. Congenital hip dislocation; passed as "just mobile." Oesophageal stricture; had escaped detection when investigated in 1969, though visible in films taken then. Recognised by barium studies in 1973.

Better supervised in Bath (1 case)-Recurrent urinary infection. This child's postal specimens seemed unreliable. Had already been investigated and was known to have normal urinary tract. She was, and remained, well.

General practitioner dissatisfied with management (2 cases)-Abdominal pain; referred by general practitioner to ENT surgeon. Abdominal pain; child now attends child guidance clinic.

Failure of management (5 cases)-Enuresis; moved from area before being supplied with buzzer. Enuresis; failure to follow up treatment with buzzer. Soiling (constipation with overflow); sequence of miscarried plans and misunderstood instructions ? entirely our fault. Obesity; failure (at first two attempts) to get patient to attend in Bath to see dietitian. Headaches; failure to send further appointment after patient had defaulted once. Family doctor reported that he had done well.

\section{FAILURE OF CONTACT AND COMMUNICATION}

Failure to maintain contact (5 cases; family doctor's opinion)-Spina bifida with social problems; was already attending another consultant. Paroxysmal tachycardia; was already under care of another paediatrician. Bronchiectasis (postoperative). Fits and tantrums. Recurrent upper respiratory infection.

Failure to maintain contact (1 case; parents' and doctor's opinion)Ehlers-Danlos syndrome.

Failure of communication ( 5 cases) - No copy in records of letter that should have been written to parents. No copy in records of letter that should have been written to doctor ( 2 cases). No copy in records of letter to either parents or doctor. Incomplete reporting of results of day tests (these should already have been reported from the ward in Bath).

No harm came to the six children where there was a failure to maintain contact. Continuing supervision at the local hospital would have been preferred; there was no wish for this to be transferred to Bath. The five failures of communication were equally innocuous, since all the children were well. Such failures are difficult to prevent completely but they are, in fact, less frequent in the country clinics than in Bath. There is closer liaison between the doctors (we may meet over coffee in matron's office) and a closer tie between hospital staff and the local population. Furthermore, some country clinics are regularly attended by health visitors.
The group that causes anxiety is the 12 patients $(1.2 \%)$ for whom medical care was not satisfactory. The important question is whether the errors would have been prevented by seeing these patients at the district general hospital. The battered and "pre-battered" babies were admitted to the ward for investigation and no real diagnostic delay occurred. They are classified as unsatisfactory because the full diagnosis was not suspected at their first attendance, but this might have occurred equally easily in Bath. The congenital hip dislocation would also have been missed at this stage in Bath, since I do not $x$-ray all babies with unusually mobile hips. In the case of the oesophageal stricture there was gross diagnostic delay, due in part to failure to interpret correctly the films in 1969, when the peptic stricture of the oesophagus was already present. Patient and consultant tolerated the continuing and surprisingly mild symptoms and would have done so just as readily in Bath as at Frome. Similarly, in the other eight cases there was no indication that attendance at the country clinic contributed at all to the reason for regarding the consultation or its outcome as unsatisfactory.

In no single case, therefore, was there evidence that the smaller outpatient rooms or lack of ancillary facilities led to any patient getting a service inferior to that which he would have received at the district general hospital.

\section{Discussion}

This survey plainly reflects my policy, but the findings and even the practice may not be exceptional. Gruer ${ }^{3}$ commented on the large number of patients being discharged after clinical consultation; she also mentioned that a definitive diagnosis was made at the first consultation in the same proportion of patients seen in the Edinburgh main hospitals as in the cottage hospitals. She reviewed many specialties, including paediatrics, but did not separate them. Forsyth and Logan ${ }^{6}$ reported that $53 \%$ of paediatric patients discharged after the first consultation had needed no tests at all; even $30 \%$ of those kept under review went without investigations.

Thus much outpatient work is pure consultation, needing no ancillary support. This is probably even more true in the medical care of children than in that of adults. For children the information provided by the family doctor may be enough to make a diagnosis, and the consultation may really have little function except to support him in the management of a situation that may be basically unalterable. After the doctor's letter, the consultant's history taking is crucial, particularly when the medical examination may be far from rewarding, with a child tense and unco-operative; similarly, some tests may founder on the difficulty of collecting an adequate specimen from a crying or incontinent child. The report of Hampton et $\mathrm{al}^{7}$ accords with our experience; they found that the referring letter and good history taking led to the correct diagnosis in 66 out of 80 new patients; laboratory help was essential for only six.

It might be objected that family doctors would select the patients for referral to local or central hospitals according to their assessment of the need for investigations. During our earlier survey ${ }^{1}$ we attempted to ascertain the criteria by which the family doctors chose the clinic they patronised, and in almost all cases the reason given was social rather than medical; convenience to the patient weighed most heavily in the decision. If the practitioner was sure that investigations were going to be needed he would refer the child for admission rather than make an outpatient appointment, which would be a waste of a journey. We have no reason to believe that the "case material" in the central clinics differs from that at a peripheral one. Urgent "extras" are frequently seen at both.

Clinics of the type studied here are a great support to the family doctors who have charge of these small "cottage" hospitals. Shapland ${ }^{8}$ and Weston Smith et al ${ }^{9}$ are emphatic about the value of these hospitals to the community and the doctors, and the benefit is greatly increased by the facility for consultants to visit for clinics.

Medical students (never more than two at a time) are often taken to these clinics. The pressure is often too great for full discussion of the cases seen (except in the coffee interval and the 
half-hour drive back to Bath), but students almost invariably express pleasure at the pattern of medicine practised, the happy and easy doctor-patient relationship, and the satisfactory holistic approach at clinical level to the total problems the patients present.

The Lancet $^{10}$ urged the need for audit of outpatient facilities and efficiency, and Glass ${ }^{11}$ contended that, despite difficulties, cost-benefit analysis of medical work should be attempted.

We have already shown that such clinics are favourable from the point of view of cost-benefit. This paper shows that nearly $98 \%$ of such consultations were satisfactory from the medical point of view. This demonstrates that the benefit of cost and convenience is not bought at the price of an inferior service to the patient. In fact, in many ways the service at peripheral clinics may be better. The numbers failing to attend are lower at country clinics and problems of communication are generally less. These aspects are under further detailed investigation.

These clinics could be conducted quite as adequately in a health centre or the premises of a group practice, ${ }^{2}$ with the added advantage of a close liaison with the family doctor. This would, however, demand more time per patient to allow for discussion-in other words, for the teaching role of such a clinic. It would, therefore, not be possible to see so many patients.
The information here reported should be supplemented by similar surveys in other specialties, so that the value of consultant work in peripheral hospitals, health centres, or in practitioners' premises may be more clearly seen. Such data should be of considerable value for planners.

The expenses of this survey were met by a grant from the Bath Area Medical Research Trust, for which I am most grateful. I also thank the family doctors and medical records officers, who helped so willingly.

\section{References}

${ }^{1}$ Kerr, H M, Lawson, C W, and Weller, S D V, submitted for publication.

${ }^{2}$ Marsh, G N, and Tompkins, A B, British Medical fournal, 1969, 2, 106.

3 Gruer, R, Lancet, 1971, 1, 390

${ }^{4}$ Bailey, S M, Evans, D W, and Fleming, H A, Lancet, 1975, 2, 57.

5 Leonard, J V, Clayton, B E, and Colley, J R T, British Medical fournal, $1975,2,662$.

${ }^{6}$ Forsyth, G, and Logan, R F L, Gateway or Dividing Line? London, Oxford University Press, 1968.

${ }^{7}$ Hampton, J R, et al, British Medical fournal, 1975, 2, 486.

8 Shapland, D, World Medicine, 1975, 10, 45.

9 Smith, J W, et al, British Medical fournal, 1973, 2, 471.

10 Lancet, 1973, 2, 137.

11 Glass, N J, Health Trends, 1973, 5, 51

\title{
Letter from . . . Zürich
}

\section{The 8th of December 1974}

\author{
PETER PAUL RICKHAM
}

British Medical fournal, 1975, 4, 393-394

I am still surprised that the happenings of the 8th of December 1974 did not cause even a ripple amongst medical men outside Switzerland. Certainly I have not yet met a British doctor who had any idea that something extraordinary happened then. Perhaps with galloping inflation and unemployment coupled with the rapid decline of the last remnants of the National Health Service, British doctors have other things to think about. Nevertheless, I thought that they might momentarily have stood still and wondered.

Before I tell you about the 8th of December I must very briefly explain the workings of Swiss democracy. Switzerland is a direct democracy: government and parliament can propose new laws, they can debate and vote on them; but they cannot pass them. Only the people, aptly called here the "sovereign," can pass laws. New laws can be proposed by government and parliament, but they can also be proposed by individuals or groups of individuals-for example, a political party-asking for a referendum, provided they have enough signatures to support their petition.

Switzerland is the land of free enterprise and the medical services are no exception. Ninety-five per cent of the people

Kinderspital, Zürich

PETER PAUL RICKHAM, MS FRCS, professor of paediatric surgery are insured by private insurance companies for ambulant and hospital treatment. I have no doubt that the standard of medical care is superior to that of any country I have visited, but there are imperfections in the system. There has long been friction between insurance companies and general practitioners about some payments. Hospital charges have doubled since 1970 and so insurance premiums have had to be raised and the state has had to pay a larger and larger share of the costs.

For a long time the socialist party, one of the three large parties in this country, has vociferously agitated for a state medical service. Enough signatures for their petition were quickly collected. They wisely refrained from saying in detail how much this would cost the tax payer (already the proportion of the gross national income spent on health is much higher in Switzerland than in Great Britain) and, although they suggested that the insurance companies could somehow be incorporated in their scheme, there was no doubt in anybody's mind that what they were after was a state medical service similar to that in Britain or Sweden.

The coalition government was apparently worried that the referendum might succeed and, as they usually do, put up counterproposals. What, they asked, did the doctors suggest? To an outside observer the reaction of the doctors was rather bewildering. The medical profession was disunited. Different health service plans sprouted like mushrooms after the rain. For somebody who had experienced 1948 in Britain there was a sense of déjà vu. Every doctor I talked to privately was convinced that the present system offered much better patient care than any of the new schemes, but to say it loudly was not progressive and would harm the medical man's "image." 